\title{
AS PSICOPATOLOGIAS DO APOIO: AUTISMO, ADICÇÃO, SOMATIZAÇÃO
}

Eliane Allouch

Psicanalista, mestre

de conferências

habilitada em

psicopatologia,

Universidade de

Paris XIII

Tradução: Simone

Perelson

RESUMO: A partir de vinhetas clínicas, testemunhos escritos de pacientes e pesquisas de outros psicanalistas, a autora coloca em relevo as síndromes do autismo, da adicção e da somatização para demonstrar que estas apontam diferentes graus do fracasso do duplo e primeiro apoio das pulsões sexuais sobre o outro e as funções corporais. Do mesmo modo, o paradigma auto-erotismo-autismo se refere às patologias não psicóticas que constituem o autismo, as adicções e as somatizações. Verifica-se assim que o objeto autístico, adictivo e o objeto do paciente somático não representam o objeto primário, eles o substituem e criam as condições paradoxais de uma repetição autística de destruição do outro.

Palavras-chave: Autismo, adicção, processo somático, paradigma auto-erótico/autístico.

ABSTRACT: Psychopathologies of support: autism, addiction and somatization. Using clinical illustrations of patients' written testimonies and other psychoanalysts' researches, the author highlights that autistic, addictive and somatic syndromes originating different degrees of failure. This failure respects the first dual analyses of sexual drives on the other and the body functions. Likewise, the auto-erotic-autistic paradigm deals with non psychotic pathologies which are autism, addictions and somatic diseases. Thus, it is verified the autistic or addictive object, or the somatic patient do not represent the primary object; they replace it and create the paradoxical condition of an autistic repetition of the destruction of the other.

Keywords: Autism, addiction, somatic process, auto-eroticismautism paradigm. 
"Nasci furado $[\ldots]$ preciso

de ódio e de inveja, é a minha saúde."

MICHAUX, 1998

7 éline, a analisanda (ALLOUCH, 2002), me fez considerar, mais do que qualquer outra, uma aproximação entre autismo, adicção e somatização. Ela sofria de sérios distúrbios do sono, de anorexia com amenorréia, ${ }^{1}$ assim como de um câncer do seio do qual não tratava. Dirigiu-se à análise tardiamente, por volta dos 40 anos, como um último recurso contra o "irreversível", como diz desde o nosso primeiro encontro, designando assim um suicídio possível. Para minha surpresa, detectei nela uma síndrome autística com profunda perturbação do contato tátil e afetivo, tal como descrita por L. Kanner (194243), síndrome cuja resolução foi determinante. Tal fato tornou-me mais atenta a outro(a)s pacientes que apresentassem fenômenos de alcoolismo, consumo de drogas ou doença somática.

A hipótese que se me impôs era que estas três síndromes - autismo, adicção e somatização - poderiam muito bem derivar, em níveis diversos, de fracassos do apoio das pulsões sexuais nas funções corporais, sendo o autismo o seu paroxismo. O que estaria em questão seriam os fracassos do acesso a uma constituição auto-erótica suficientemente portadora de um sentimento-sensação de existir contínuo, ${ }^{2}$ devido à falta de cumprimento do processo alucinatório primário. ${ }^{3}$ Tais síndromes vêm colmatar, de modo patológico, estados de desamparo apocalíptico insuportáveis, fontes de reações de autoconservação paradoxais, em que os únicos afetos que ainda se desenvolvem são o terror, o ódio, a impressão de morte interna e a falta de confiança em si e no outro. Como em toda situação patológica, o impacto de Tanatos nestas três síndromes prima sobre Eros. A compulsão de repetição parece ter funcionado sem contenção alguma, sem apoio em um suporte libidinal que não fosse nem demasiado nem insuficientemente estimulante.

Spitz mostrou com que rapidez um bebê, privado de suficiente suporte, pode deixar-se morrer, passando por todos os graus do hospitalismo, entre os quais a retração depressiva ou odienta não detida por uma fixação a um estado de retração autística, fixado ao processo de alucinação negativa. Em seu artigo “A criança mal acolhida e sua pulsão de morte”, Ferenczi (1929/1982, p.76-81),

\footnotetext{
${ }^{1}$ A anorexia é hoje considerada essencialmente uma adicção. Ela poderia ser encarada como um estado limite entre adicção e somatização.

${ }^{2}$ Expressão winnicottiana, à qual acrescentei o termo sensação, suporte do sentimento experimentado, que empresta seu modelo de representar à sensação.

${ }^{3} \mathrm{Cf}$ minha concepção do autismo como fixação ao processo de alucinação negativa (ALLOUCH, 2002).
} 
por sua vez, descrevia, conjuntamente à fraqueza do gosto de viver o determinismo da pulsão de morte em casos de epilepsia, de asma brônquica de origem nervosa, de inapetência total com emagrecimento, de uma disposição aos resfriamentos, de frigidez e de uma inclinação à especulação cosmológica. Em 1974, as pesquisas sobre a patologia do primeiro ano conduzidas por Kreisler, Fain e Soulé evidenciaram que as cólicas dos primeiros meses, a insônia do primeiro semestre, o mericismo, a anorexia e os vômitos, o megacolo funcional, o espasmo do soluço e a asma do recém-nascido podem ser descritos como faltas do apoio, com sobrecarga ou carência auto-erótica. Para os autores citados, estas perturbações aparecem na maior parte das vezes como prefigurações psicóticas ou perversas e, talvez, a propósito do mericismo, como uma psicose autística. Em 1990, contudo, Tustin sustentou a idéia de que as perturbações somáticas constituem o esboço de uma saída do autismo, quando o paciente começa a sentir que alguém pode cuidar delas de modo apropriado (1990/ 1992, p.172). Enfim, em 1997, em artigo intitulado “Autismo: aspectos autísticos na farmacodependência e nas doenças somáticas”, Rosenfeld avançou a tese da atualização das sensações corporais autísticas nestas duas síndromes. Ele aclarava que "o sintoma psicossomático dá a estes sujeitos uma sensação de identidade (a sense of being) similar às sensações corporais que as crianças autistas buscam ao introduzir em seus corpos ou ao esfregar nele objetos duros" (1997, p.176). De minha parte, quero destacar que não apenas as somatizações graves podem ser tentativas ou esboços de uma saída de perturbações autísticas, assim como defende Tustin, mas que isto também ocorre no que diz respeito às adicções. Que as adicções e as somatizações proporcionam um Ersatz de identidade, ${ }^{4}$ como sublinha Rosenfeld, apenas reforça a hipótese avançada. Do mesmo modo, esta linha de pesquisa está de acordo com a que indicava Fédida, ao propor a constituição de um paradigma auto-erotismo-autismo, que concerniria patologias não psicóticas (FÉDIDA, 1990, p.395-413).

Após ter lembrado as principais características do autismo, buscarei seus pontos de convergência com casos de adicção e de somatização. Para isto, me apoiarei em certo número de exemplos de minha prática pessoal, mas também em escritos de pacientes e em observações de outros pesquisadores.

\footnotetext{
${ }^{4} \mathrm{O}$ termo identidade me parece muito forte, proponho em seu lugar o de ser: um Ersatz do sentimento-sensação de ser. Em “Trahison du corps”, eis o que Michaux (1994) afirma: "Faço companhia a um fleimão. /Ele, vive, engorda, se exalta, fura, queima, consome, invade, azorraga, enxamea. Resumindo: ele vive. / Ele é infatigável.” (1994, p.841) Tal asserção confere com a (tirar isso) uma observação de Winnicott: "Um dos objetivos da doença psicossomática é retirar o psiquismo do espírito e fazer com que ele retorne à sua associação íntima e primitiva com o soma." (1949, p. 78).
} 


\section{A SÍNDROME AUTÍSTICA}

Quando a encontramos, a síndrome autística confronta à presença de sujeitos autistas cujas manifestações podem variar de maneira considerável, comportando ou não a possibilidade de recorrer às palavras, sem que estas correspondam a um verdadeiro valor de troca identificável. Em certos casos, tais como o de Zéline ou da norte-americana autista Temple Grandin (1986/2001), pode acontecer que suas verbalizações comportem grande inteligibilidade, mas seu conteúdo seja operacional, hiper-racional e como que desnudado de afetos. No plano corporal, encontramos a mesma polaridade: eles podem ser ou murados em um "fenômeno de segunda pele", coisa que os priva de quase toda corporeidade (voz, gestos, olhar, etc.), tal como descreve Bick, depois Tustin (1972/ 1977, p.60), ${ }^{5}$ ou engajados em uma hiperatividade funcional compulsiva, global e eficaz, ou ainda localizada sob forma de estereótipos. Tanto no plano do verbo quanto no do corpo, esta dupla polaridade corresponde a uma incapacidade de troca afetiva e do contato com o que é vivo e mutável, como observava Kanner. A ocupação mais importante deles concentra-se na busca de imutabilidade do seu meio ambiente, o que é tiranizante para eles próprios e para os que com eles convivem (KANNER, 1942-43, p.258). A insistência nesta busca de imutabilidade equivale apenas, para eles, à necessidade de experimentar ao menos uma sensação, senão um sentimento de existir.

Seu principal sistema defensivo ou, como prefere Tustin, sua principal "reação protetora”, é o recurso massivo à "inserção em cápsula (ou em concha) autogerada e dominada pelas sensações” (1990, p.113 e 65). A sensação tátil, particularmente, comporta ao mesmo tempo atração e terror. Em seu livro Se me tocam, não existo mais (Nowbody nowhere) em 1992, a autista australiana Donna Williams esclarece que "era o medo de ser desapossada do seu [meu] próprio mundo que a [me] impelia a rejeitá-lo, para trocá-lo por uma concha vazia e sem emoção" [...] "fechava-me em mim mesma, era também os outros que eu fechava do lado de fora" (p.130). Do mesmo modo, ela estabelecia uma espécie de barreira ou de tela pára-excitações da ordem da alucinação negativa, que não transforma as sensações em representações-coisas ou em representações de afetos. Permanecem apenas as sensações, que são exacerbadas por sua não-descarga ou sua não-projeção em representações, precondição aos atos de troca, mesmo que indiferenciados, com o outro ou consigo mesmo. Em Uma alma prisioneira, escrito

\footnotetext{
${ }^{5}$ Para E. Bick, um recém-nascido, cuja capacidade primária de conter a alimentação é perturbada, busca "conter-se de modo muscular, fabricando uma segunda pele para substituir o continente apropriado que constitui sua própria pele". Está bem entendido que "a formação da pele" normal "se produz quando a criança interiorizou experiências tranqüilizadoras e asseguradoras suficientes com a mãe”.
} 
em 1993 graças à comunicação facilitada pelo computador, a autista alemã Birger Sellin constata que o que está em questão é o "corte do homem com suas primeiras experiências essenciais, por exemplo chorar” (1993/1994, p.102). Ele não pode exprimir-se emocionalmente diretamente pelo corpo, mas apenas a partir de "realidades de segunda ordem" (p.181), tal como a escrita a máquina interposta enquanto que uma outra pessoa, excessivamente discreta, o ajuda. Único modo de descarregar sua tensão vital das crises clásticas que o tornam semelhante a um animal. Em Minha vida de autista, de Temple Grandin, a autora confirma tal economia somatopsíquica. No que concerne à pesquisa que nos interessa, ela esclarece que, caso retenha seus gritos, “pega uma herpes” (1986, p.178), sofre de crises colíticas severas, de eczema ou de crises de nervos, expressões de sua agressividade" (1986, p.155). [A propósito, notemos que estas observações somáticas de Temple — que podemos aproximar das de Zéline, mas também das de Fritz Zorn (1977/1979) — , que substituem uma crise clástica autística, mostram a origem comum dos fenômenos autísticos e dos processos de somatização.] De qualquer modo, todos se descrevem como hipersensíveis, mais do que angustiados: o "mundo dos outros excitava excessivamente meus sentidos”, escreve Temple Grandin (1986, p.48). Para fugir desta excitação e dos estímulos exteriores, ela indica, junto com outros, o recurso a condutas de auto-estimulação, tais como girar em torno de si mesma, se automutilar, comprimir-se em um alçapão, inicialmente destinado a marcar o gado, etc., ou seja, utilizar qualquer dispositivo que permita auto-acalmar-se encontrando limites, um continente, “além do princípio do prazer" (FREUD, 1920). ${ }^{6}$ Encontramos aqui o destaque dado por F. Tustin à auto-sensualidade dos autistas, como formação de suplência para se conter e se sentir existindo em um local dado e em continuidade.

O outro mecanismo defensivo do autista é produzir o que Tustin chama de “objetos e formas autísticas” (TUSTIN, 1990, p.36-37) que constituem, conforme apontado pela autora, “espécies de tranqüilizantes auto-induzidos, que são utilizados como se consistissem em substâncias corporais manipuláveis, que estão constantemente sob seu controle tirânico” (1985, p.221-246); eles constituem proto-objetos, proto-imagens, que "podem ser consideradas (segundo ela) como uma espécie de alucinação do tocar” (1989, p.8), ${ }^{7}$ equivalente precário de uma pele psíquica ou de um eu-corpo, que proporciona

\footnotetext{
${ }^{6}$ Neste texto, Freud sustenta especialmente que "a compulsão de repetição [que] nos parece mais originária, mais elementar, mais pulsional que o princípio de prazer que ela dispensa": cf. p.63-64.

${ }^{7}$ Esta expressão alucinação do tocar parece-me contestável: estas sensações-objetos e sensaçõesformas concernem à percepção elementar e não à representação psíquica. O grifo é meu.
} 
certa identidade de superfície ou identidade adesiva. ${ }^{8}$ Eu aproximo estas "substâncias corporais manipuláveis" dos autistas do recurso às drogas, substâncias igualmente manipuláveis, que McDougall designa de "neo-necessidades" ou "neo-objetos" que visam essencialmente "a se livrar (de certo modo, como o autista) de seus estados afetivos "de angústia e de morte interna (MCDOUGALL, 1996, p.232-233).

No autista, o estado terrífico que dá lugar aos dois mecanismos de defesa evocados é tal que vários entre eles, assim como terapeutas (Tustin, inclusive) o comparam a um buraco negro, como observamos em física. Sabemos que a força de gravitação dos buracos negros é tão forte que ela impede até partículas virtualmente desprovidas de massa, os fótons, de lhe escapar. O terror essencial do autista é de ser aspirado e de desaparecer em um abismo, em um sem-fundo como este. Zéline apreendia este "sem fundo" diretamente em seu corpo. Ela reclamava de sua impressão profunda "de ser exterior a seu próprio corpo" ou ainda de "ser uma construção sobre um sem-fundo", estado de alucinação negativa de seu corpo em suas origens (ou seja, das primícias do eu-corpo), que a fazia sentir-se fundamentalmente "fora", como dizia, e sem desejo algum (ALLOUCH, 2002, p.121). Sustentei alhures que esta negação do corpo ou do figurável representava um fracasso da via do "contato direto (das Beruhrung im direkten)" e do sentido do real ou do familiar, via designada por Freud (em "as relações de dependência do eu”) como uma das duas "vias de penetração do isso no eu” (FREUD, 1923), que chamei de via econômica das sensações e do afeto (ALLOUCH, 1999, p.163-174). Ela é o vetor dos dois primeiros tempos do auto-erotismo, como Freud teoriza em $A$ pulsão e suas vicissitudes (1915, p.174). O terceiro e último tempo deste destino é o da "instalação de um novo sujeito” (1915), que designa a presença narcisizante, pois simbólica, do objeto primordial. A qualidade de presença deste "novo sujeito" permitirá ou não o retorno da pulsão e sua fixação no próprio corpo sob a forma de zonas erógenas mais ou menos marcadas por Eros ou Tanatos. Quanto mais marcadas por Eros, estas tornarão o corpo presente ao próprio sujeito até o ponto de constituí-lo como si, ou seja, como identidade subjetiva; quanto mais marcadas por Tanatos, o corpo será negativado, ou mesmo rejeitado tal como um objeto de nojo, levando ao fracasso da constituição da subjetividade primária. Este foi o caso de Zéline, como de qualquer autista. ${ }^{9}$ Em caso de adicção e de somatização, como veremos adiante, o fracasso da

\footnotetext{
${ }^{8}$ Emergindo de um estado autístico, Haag (1985) observa que 'o ser colado à' do autista só pode ser substituído pelo 'ser violentamente penetrado em seu interior'.

${ }_{9}^{9}$ Diferentemente do autismo, os estados de psicose infantil permitem um acesso ao autoerotismo e, portanto, à identidade subjetiva enquanto objeto parcial do Outro.
} 
subjetividade primária será menos massivo, mas esta surgirá de modo furado ou clivado, sob uma prevalência de Tanatos.

O ser autista funciona sob o modelo do auto sem Eros, ou seja, de um eureal-inicial" (FREUD, 1915, p.180) que não ascende ao "eu-prazer-purificado" (p.181), mas essencialmente a uma espécie de eu-desprazer compulsivo autoconservativo, situando qualquer estímulo como sensação de desprazer, ou mesmo de terror, por ter experimentado a impressão de ter sido largado e não segurado, carregado e contido nestes primeiros tempos. Esta impressão primitiva de ter sido largado, mais do que separado, de modo excessivamente precoce, como formula Tustin, provoca esta outra impressão, o "desmantelamento sensorial”, do qual fala Meltzer (1975): “(...) um processo de clivagem segundo o qual elas (as crianças autistas) desmantelam seu eu em suas capacidades perceptuais separadas: o ver, o tocar, o escutar, o sentir, etc." (1975, p.212). A fixação ou o agarramento em uma sensação particular, auditiva, tátil, vestibular, etc. visa, no autista, escapar deste desmantelamento sensorial, origem de um sentimento de inconsistência, de arrebentamento ou de despedaçamento intolerável: “a angústia de minha mãe, repetiu diversas vezes Zéline, me arrebentava”, a ponto de ela não suportar ser tocada pela mãe e de os médicos consultados acabarem por colocá-la em uma manta de gesso, pseudocarapaça muscular ou "fenômeno de segunda pele”. Quanto à Temple Grandin, ela chama a atenção para o gestual pouco delicado de sua mãe e sua pequena escuta em ressonância com o corpo sensível do outro (1986, p.37, 40 e 46-47), ao mesmo tempo que a evoca como aberta e pouco conformista no plano intelectual e social. Ambas, Zéline e Temple, atribuem ao pai uma presença mal existente, mais do que real.

Assim, o acento colocado pelos autistas na falta de contato afetivo fundado no tátil bruto e no vazio de um estado de alucinação negativa petrificado, que exclui o apoio no corpo, não expõe uma simples negação de um traumatismo de abandono ou de extirpação muito precoce, mas sobretudo uma forma de autoconservação paradoxal, que visa assegurar um sentimento-sensação de continuidade de ser fora do laço ao outro. Uma clivagem radical se dá sobre o laço primário ao objeto libidinal, e, do mesmo modo, sobre o eu-corpo, conseqüentemente, com a manutenção sob tensão da pulsão, que permanece excitação diretamente sobre a superfície do corpo, que não pode, então, projetar-se para dar um eu-corpo, assim como Freud o define em nota de 1927: “o eu é finalmente derivado de sensações corporais, principalmente das que encontram sua origem na superfície do corpo. Ele pode ser considerado uma projeção mental da superfície do corpo, e, mais, como vimos acima, ele representa a superfície do aparelho mental" (FREUD, 1923, p.238). 


\section{A SÍNDROME DA ADICÇÃO}

De modo análogo, mas de maneira menos radical do que a fixação nas sensações e a criação de formas e de objetos autísticos, a conduta, ou o objeto adictivo, seria encontrado para permitir também uma sobrevida da identidade subjetiva. Mas ele tampouco assegura, entre a necessidade e a espera do outro, a distância necessária para que o fantasma, ou seja, o pensamento plástico e figurativo - a textura narcísica - possa se desenvolver apoiando-se no sensorial e no gestual e constituir uma tela sobre o vazio do estado de ser separado, ou melhor, largado antes da maturação necessária. A elaboração desta tela plástica e figurativa condiciona a emergência de uma corporeidade sensível, desligada e sexuada, assim como a de uma palavra plena às quais os sujeitos farmacodependentes só ascendem com dificuldade, penosamente e de maneira instável. À sua revelia, de maneira compulsiva, ou seja, traumática, o toxicômano, o alcoólico e qualquer outro adicto repetem nas modificações coenestésicas causadas pelo pharmakon ("substância maléfica e filtro de esquecimento") (DERRIDA, 1968, p.23) ou ainda por uma conduta passional, estimulações indiferenciadas, misturando o corporal e o emocional. Estas estimulações indiferenciadas são análogas às excitações precoces que acometem o recém-nascido incapaz de desemaranhá-las. As estimulações teriam sido vividas pelo bebê sem que lhe tivessem fornecido suficiente nomeação, discriminação ou ordenamento. As excitações psicocorporais (os elementos beta teorizados por Bion, ou ainda o que Piera Aulagnier designou como atividade pictográfica) teriam permanecido em parte sem significação, tornando-se, assim, traumáticas. Elas constituem pontos permanentes de apelo compulsivo da presença do outro em sua forma mais concreta, tal como uma coisa-substância ambígua, como o pharmakon, ao mesmo tempo veneno e remédio. A droga ou o encontro do objeto passional exalta esta presença-substância do objeto primário através das sensações alucinadas, que não chegam a se transmutar em representações figurativas estáveis ou em representações de palavras constitutivas de si ou de objetos culturais, salvo no caso de um artista genial como Henri Michaux. Em Conhecimento pelos abismos, ele evoca "a torre de babel das sensações" da droga em que "milhares de informações chegam, concordando com nada, intraduzíveis". Estas informações, aclara Michaux, só interpelam o intoxicado "imprudentemente", (segundo) "a língua específica de cada um dos sentidos, [...] em odores, em sons, em fricções, em formigamentos, em vislumbres, que apresentam-se apenas a ele" (MICHAUX, 1967/1984, p.211).

Assim, de modo análogo, embora menos radical do que para o autista, diferentes zonas corporais são colocadas sob tensão, carregadas de excitações, mas permanecem inertes e mudas. O recurso ao pharmakon é necessário para que a excitação destas zonas possa tornar-se representações e, por meio disto, aliviar 
o sujeito, dando-lhe acesso a uma espécie de atividade psíquica psicodélica. Sem este recurso, há o não-desmembramento da pulsão segundo os três tempos do processo auto-erótico; como no autista, estas zonas corporais marcadas pela prevalência de Tanatos não geram uma atividade representativa de ordem fantasmática e proto-simbólica, a partir da qual se constituiriam as bases páraestimulantes da trama narcísica e do eu-corpo. Ao contrário, as excitações intraduzíveis, negativantes, destas zonas provocam trauma, ou seja, buraco, buraco(s) que ameaçam incessantemente o eu (que pôde mais ou menos se estabelecer) de desmoronamento diretamente em suas origens, diretamente no sentimento-sensação de continuidade de ser ou de identidade subjetiva.

Délia encontrou-se assim, aos 17 anos, mais uma vez, com um namorado que tinha uma doença mortal. Ela se esforçava para puxá-lo para a vida, apesar de um imenso desespero, contestando os tratamentos médicos até o momento em que, sem dúvida convencida da morte iminente de seu namorado, ela "cortou" com ele. Pouco tempo antes, havia procedido do mesmo modo para interromper a psicoterapia: notificou-me o mais brevemente possível, através de secretária-eletrônica interposta, que não viria mais. Dez anos mais tarde, telefonará para retomar um trabalho terapêutico. Após ter tentado "se sair sozinha”, ela estava agora convicta de que não era possível. Pedia-me para retomar o trabalho interrompido, mesmo sabendo que ainda era passível de "cortá-lo" novamente.

Sempre centrada no tema da morte - morte próxima de seus pais, morte de seu cachorro, morte de seus avós — projeção do sentimento-sensação de desmoronamento do qual havia fugido, projetando-o até então em seus amigos doentes, ou tentando negá-lo com o "baseado" (cigarro de canabis, misturado a uma resina), o álcool, os cigarros, o meio "festivo" das drogas, as práticas intensivas das percussões e da natação (a ponto de ter um quisto no braço), comer até não poder mais, jogar flíper — tudo isto para não pensar mais, ser anestesiada psiquicamente, mas submergida por suas próprias sensações reais ou alucinadas - ela chega aos 20 anos com a constatação de que se autodestruía e de que gostaria de poder "fazer outra coisa de sua vida": "o baseado impede de associar duas idéias ou de defender uma”... mas ela gostaria de parar de "se quebrar", de "se acabar" com a droga, embora este seja o único modo pelo qual pode abandonar-se com os outros, não mais ter medo do desconhecido, medo da vida, medo de não estar viva, medo de suas rugas, medo de desmoronar: é por isso que foge dos outros, não pode falar com eles, como conta ao longo das sessões: "não quero que eles me vejam desmoronar". "Quando enrolo meus cigarros, quando preparo um baseado, é o melhor momento, pois só penso nisso." Assim, todas as suas práticas têm um único objetivo, fixá-la em suas sensações ou em um ritual para existir ao menos na superfície, tal como uma 
autista. "É verdade, diz ela, que gosto do odor da droga... as folhas de canabis ou o álcool me ligam, me excitam." (Em outras palavras, ela ascende em desespero de causa, se não ao prazer, a um gozo total, tal como uma delirante. Isto significa que o fenômeno da adicção psicotiza traços autísticos, ou seja, traços do fracasso, maior ou menor, do apoio).

Délia evoca tudo isto chorando com abundância. Às vezes, no final da sessão, dirá que, enfim, uma sessão “é como um baseado” mas, no conjunto, é bastante ambivalente quanto às suas sessões, tão ambivalente quanto no que diz respeito à sua mãe: "gostaria de comê-la, que fôssemos um único corpo, um único ser; eu não teria, assim, mais medo da morte, de ser separada”; mas tem também medo dela: "minha mãe é como uma aranha”; "ela fica à espreita de minhas sessões" (aliás, a mãe havia me telefonado para vir às sessões com sua filha). Délia emocionava-se e exasperava-se ao mesmo tempo com sua mãe. Tinha medo por ela mas, ao mesmo tempo, desejava que ela "enfim, desmoronasse”, que cessasse de ser hiperativa, como ela própria. Quando era pequena, sua mãe a superprotegia, a teleguiava antes que exprimisse seus desejos ou seus pensamentos. Respondia a suas angústias de criança administrando-lhes medicamentos a cada instante, particularmente lhe fazendo tomar Théralène para dormir. Mas, no final, ela sentia-se só, aliás como com seu namorado do momento: "sua presença ou sua ausência são sempre dolorosas", como diz. Lembra-se de um de seus desenhos de criança que a marcou: tratava-se de uma casa com uma menina sentada que esperava, incapaz de fazer sem sua mãe”. Aliás, esclarecerá Délia, sua mãe, falando dela quando era pequena, dissera que "me (a) sentia pegajosa”, por isso a mandava "passear" 10 na casa da tia com suas primas, mas, ela acrescenta, “tinha minha crise porque não queria dormir na minha tia”, etc. Ela deplora que seu pai não fosse suficientemente interveniente: "gostaria de ter visto meu pai mais forte. Senti muita falta dele; mas que ataquem meu pai, isto acaba comigo.

“A adicção de ausência, a espera de ninguém”, desenvolve P. Fédida (1995, p.9-21) para evocar o outro na transferência do toxicômano; o outro é ninguém, como a droga, como o objeto passional. É assim com Délia: a droga a atordoa, impede-lhe de sentir os traços invasores deixados pela mãe diretamente em seu corpo, mas ao mesmo tempo, como em um sonho, ela a torna presente em sua única materialidade de mãe colante, mas não amante, e dispensadora de sentido - fora o de morte (donde a fascinação e a obsessão de Délia pela morte). A droga repete o trauma aberto pela presença do outro, que não é senão coisa-presente, e não soube torná-la autônoma psiquicamente. Délia e sua mãe

\footnotetext{
${ }^{10}$ No original: elle l'envoyait "se promener", que traduzimos por "ela a enviava para passear". Contudo, a expressão elle l'envoyait promener, não preposicionado, quer dizer " ela a abandonava”. (N. da T.)
} 
são como irmãs siamesas coladas em um ponto de seus corpos e que aspirariam ou serem um único ser ou serem separadas - “cortadas”, diz Délia. É desse modo que ela sonha com um longo gato ferido na parte traseira de seu corpo, que se desloca mesmo assim em direção à gata excessivamente nova. Do outro lado do rio, uma gata encontra-se na grama vigorosa com seus gatinhos, tranqüila. Délia fica dividida entre as duas perspectivas de ir em direção a um ser ferido ou de dirigir-se a um horizonte de quietude onde não se é mais incessantemente excitado pela compulsão de morte do outro, enquanto que este se ativa ou se arrasta como um longo gato ferido na parte traseira de seu corpo, mas que não pode dizer o que deve ser dito.

Hoje, através da palavra, Délia distanciou-se, elaborou um afastamento com o outro da toxicomania e com o baseado. Mesmo que não os tenha abandonado por completo, pode agora passar sem eles para "ser clara”, como diz, e ligar-se a seus novos estudos: ela realiza, assim, um sonho de infância, "viver em uma biblioteca".

Na toxicomania, diferentemente do autismo, o outro existe, mas não é ninguém; é um ser-coisa ou um animal ferido, ou ainda um outro, com uma doença mortal, em todo caso, ele não fala. Mais do que uma coisa, é uma presença material que excita, que cria sensações (como no autista), mas deixa finalmente vazia e condenada, adictada ao vazio, vazio que não é ausência mas furo, mais exatamente eu-corpo furado: "tornar-se incessantemente o que se incorpora, para que o eu tenha, enfim, a ilusão de se fechar em suas próprias bordas e de resistir a uma abertura mortal”, eu diria ainda com Le Poulichet (1995, p.7).

A substância e a conduta da adicção, aqui o baseado, o álcool, o tabaco, a atividade festiva, esportiva... constituem um produto encontrado-criado pela parte primitiva clivada do psiquismo do adicto, que permanece um psiquessoma indiferenciado devido à marca deixada pelo outro primordial, ele próprio traumatizado. Este outro não permitiu que a parte primitiva clivada ascendesse à representação internalizada de uma instância pára-excitações reconfortante para restaurar, mesmo que brevemente, o estado primitivo de díade onde cessa toda excitação afetiva. A propósito do objeto adictivo, J. McDougall fala de “objeto transacional patológico” ou de “objetos transitórios” (1996, p.235). Ele se reporta, mais do que o objeto ou a forma autística, ao não-eu, mas, como vimos, um não-eu materializado, excitante, que não relança Eros, mas Tanatos. Ele é a criação do masoquismo erógeno destruidor, mortífero (ROSEMBERG, 1991/1995) destes analisandos que, como os autistas, recorrem às sensações fortes, reais (a sensação de fome, por exemplo, no anoréxico) ou alucinadas. Eles experimentam assim, em desespero de causa, algo como um sentimentosensação de continuidade de ser, escapando a um caos interno. 
Em caso de normalidade, o masoquismo erógeno primário, proveniente da fusão das duas pulsões opostas, permite reconhecer-se como sujeito, sujeito que com certeza sofre, mas não incoerentemente por desamparo, como são o adicto e o autista. Do mesmo modo que Délia espantava-se consigo própria, o adicto só pode interessar-se por um outro afetado por um estado de desamparo análogo ao seu. É o objeto primário, em geral a mãe, que se encarrega normalmente da ligação da pulsão de morte pela libido, enquanto a criança não pode ela própria fazer esta ligação. Se a capacidade de fantasia que ela (ou depois o analista) dispôs não favoreceu esta fusão necessária das bases do sujeito (durante o terceiro tempo do destino autoerótico da pulsão), traços traumáticos de desamparo se inscreverão diretamente no psiquessoma da criança, constituindo furos na textura narcísica e, em seguida, clivagens do eu; pontos de apelo adictivos, ou de desfuncionamento psicossomático, na medida que, como sustentarei com McDougall, “as duas tendências têm origens similares” (1989, p.107), assim como buscarei demonstrar.

\section{A SÍNDROME DE SOMATIZAÇÃO}

Os dois fenômenos, de adicção e de somatização, encontram-se, nos analisandos, com freqüência combinados. Conjuntamente às suas condutas de adicção, Délia sofria de grandes dificuldades para dormir e depois do sono, que em parte desapareceram após cerca de dois anos de trabalho analítico. O remanejamento da mãe interna que ela efetuou encontrava-se, essencialmente, na origem desta mudança, muito apreciada por ela. Quanto à Zéline, os três fenômenos manifestavam-se juntos, mas não tinham a mesma importância. O desaparecimento do fenômeno autístico determinou a retomada de uma dinâmica de vida sob a forma do desejo de Deus, figura do outro primordial, aquele em quem se pode acreditar, em quem se tem fé e confiança sem a menor angústia e com quem ou em quem podemos com toda tranqüilidade abandonarmo-nos por completo. Será que não encontramos nele o outro do auto-erotismo acasalado ao outro da "identificação ao pai da pré-história pessoal, (...) identificação direta, imediata, mais precoce que qualquer investimento de objeto” (FREUD, 1923, p.243) como se dá na relação do crente com Deus ou, no melhor dos casos, do recém-nascido com o objeto primário? Encontra-se nesta relação o advento ou o acesso ao que Freud dá o nome de "unidade superior do contato" (FREUD, 1913/1993, p.204) (die höhere Einheit der Berührung), própria ao que ele chama de "essência superior do homem (das höhereWesen des Mensch)” (FREUD, 1923, p.249), acesso que fracassa no autista e é mais ou menos abortado no adicto e no somatizante.

Assim como os fenômenos da adicção, as somatizações podem, segundo a distinção feita por Le Poulichet em Toxicomanias e psicanálise, as narcoses do desejo, seja 
representar simples “suplementos narcísicos”, seja constituir “formações narcísicas patológicas de suplência” (LE POULICHET, 1987, p.103-124). As primeiras são freqüentemente superficiais, da ordem do processo secundário. As segundas são profundas e de ordem secundária, na medida que derivam da desfusão pulsional que produz a perturbação somática segundo uma das duas vias curtas da descarga libidinal, a motricidade: "Esta explosão no corpo (escreve J. McDougall em Em defesa de uma certa anormalidade, que não é uma comunicação (neurótica) nem uma recuperação (psicótica), tem a função de um ato, de uma descarga que provoca um curto-circuito no trabalho psíquico. É nisso que a somatização se aparenta aos atos-sintomas, tal como as adicções (bulímica, tabagística, alcoólica, medicamentosa, etc.)" (McDOUGALL, 1978, p.162). Estes atos que levam a somatizações não deixam de encontrar um lugar na economia psicoafetiva do sujeito. Como o álcool ou a sensação de fricção autística, uma dor persistente ou o estado de doença podem tornar-se a última garantia de existir, de se identificar. Mais ainda, o “corpo estranho” que manifesta a doença, assim como Fritz Zorn (1979) designa seu câncer, constitui uma tentativa de aniquilamento dos traços negativos do outro em si, como que para criar intrapsíquica ou intracorporalmente o lugar do outro, que só pôde ser introjetado como excesso de excitações ou como um supereu desencarnado, cruel: "Quanto mais estávamos mortos, mais te amávamos $[\ldots]$ por falta de amor, eu definhava e morria [...] esta loucura desencadeou em seguida o câncer que, agora, preparava-se para destruir meu corpo” (p.100 e 209), escreve Fritz Zorn em sua obra autobiográfica intitulada Mars: "O curso de minha existência não era feito senão de espera", acrescenta Zorn (p.152). Sendo o outro interiorizado apenas sob uma forma abstrata, super-egoizante ou estetizante, a espera da qual ele fala era de ninguém: “Era sempre um 'alguém’ que eu esperava e nunca uma pessoa precisa” (p.139), ele escreve. Compreendeu tardiamente por que o homem elegante e inteligente que era nunca teve uma única namorada e nunca conheceu uma única experiência sexual, nem com mulher nem com homem. Era incapaz de amar, incapaz de desejar: "mortalmente educado", como diz, a maior parte de sua energia visava "manter o edifício de meu eu estimulado, que se esmigalhava”. "[...] Quanto mais estava deprimido no fundo do meu coração, mais eu sorria. [...] Ele buscava (até o desencadeamento de seu câncer) unicamente ser compreendido como uma parte indiferenciada do grande todo” (p.162). Este grande todo foi, em um primeiro tempo, “a casa de seus pais", depois o liceu, em seguida a universidade e, enfim, seu apartamentorefúgio. Cada um desses lugares tornava-se, como ele próprio diz, sua "concha” (p.144), em outras palavras, um "fenômeno de segunda pele" comparável ao de um autista. Ele assimila seus tormentos de mudança de "concha" aos de um "bernardo-eremita quando é preciso arriscar-se para ganhar uma nova casa expondo sua traseira a todos os predadores” (p.106). Tinha vergonha de sua nudez, 
“assim como a sexualidade, escreve, ela expõe” (p.105), enquanto que toda a sua existência se passava protegendo-se, não para viver, mas para sobreviver, tal como um falso-self radical. Enfim, ele existia como um autista dotado, "mortalmente educado", ou seja, perfeitamente educado: "Eu conseguia muito bem fazer todo mundo rir, mas eu próprio não ria nunca”, observa. Como a autista Birger Sellin, Zorn não podia existir afetivamente no nível do seu eu-corpo, ele era privado de qualquer experiência sensual de base (até a sua psicoterapia; ele abominava os jogos do corpo, tal como a ginástica ou a dança, que praticou posteriormente). Ele sobrevivia através de um pensamento formal estetizante ao qual renunciou quando apreendeu a catástrofe a partir da qual este era construído, que o privava de toda vida pulsional em seu corpo. Ao chegar a este ponto, revoltou-se e o que surgiu foi o ódio em relação a toda a ideologia da sociedade burguesa suíça da costa dourada do lago Léman, da qual seus pais eram a própria quintessência (o sobrenome Zorn significa precisamente irado). A partir de então, ele não parou de lutar a fim de não ser como eles, mas, constatou: “meus pais estão alojados em mim, metade corpo estranho e metade eu próprio, e [eles] me devoram, assim como o câncer que me devora é metade parte estranha de meu organismo e metade corpo estranho no interior de meu organismo" (p.238).

Fritz Zorn considera seus pais internos como a parte destrutiva em ação nele mesmo, que deve extirpar a fim de viver normalmente e, talvez, chegar a tempo de parar o processo canceroso. O que ele não poderá fazer, apesar de um trabalho psicoterapêutico obstinado. Morreu aos 32 anos, tendo ao menos sustentado, através de seu testemunho, a comunicação de um sentido para sua existência tal como a concebia. Portanto, se a somatização pode constituir um preâmbulo ou uma tentativa de saída do estado autístico, como defende, entre outros, Tustin, o terapeuta encontra-se acuado nos limites de sua ética quando se engaja em tal aventura.

Contudo, o texto de Fritz Zorn, a exemplo das memórias do presidente Schreber, constitui um documento básico para o estudo de casos comparáveis. Penso, particularmente, em duas de minhas analisandas, também atingidas pelo câncer. Como Fritz Zorn, ambas existiam à maneira de falsos-selfs muito desenvolvidos, cuja parte psíquica primitiva havia sido quase que sufocada por um funcionamento psíquico secundário bastante operacional e adaptado às exigências sociais de pais rígidos e não receptivos às necessidades de crianças muito pequenas. Uma destas duas analisandas, Annie, dirigiuse à análise logo após sua aposentadoria, com 60 anos, decidida a engajar-se em um trabalho sobre si própria para deixar de viver em função das exigências dos outros. O homem que ela amava tinha acabado de deixá-la por uma mulher muito mais jovem, com quem queria ter filhos. Ao evocar tudo isto, Annie não abandonava o sorriso que mantinha como uma criança (ou como 
Zorn). Até então, ela havia suportado sua insatisfação consigo própria dedicando-se aos outros e escrevendo um diário que não será publicado, apesar de seus esforços. Após um ano de análise, sua ginecologista diagnosticou nela um câncer no seio. Após quatro anos de remissão em relação a este primeiro câncer, que retornou até anular-se sem que tivesse que recorrer à ablação do seio, ela sucumbiu rapidamente a um câncer que afetou um de seus rins e seu fígado. Contudo, o que sublinhava como positivo ao longo destes dois estados cancerosos, é que, enfim, ela ousava pedir ajuda. Os outros lhe pareciam agora acessíveis a uma demanda de solicitude que ela própria apresentava, ela que até então estava condenada a sacrificar-se sem nunca esperar a contrapartida.

No início de sua análise, ela trouxe-me um conto que, après coup, me parece transcrever, de modo metafórico, seu funcionamento psíquico clivado. Suas duas partes psíquicas estão representadas no conto por um "grande urso que não era malvado, que sabia lamber, mordicar, acariciar sem parar”, como ela própria fazia com as pessoas que lhe eram próximas, e o outro por uma mulher sem braços nem mãos, que buscava, como ela mesma descreve, aliviar seus sofrimentos. O grande urso figurava seu falso-self e a mulher sem braços nem mãos seu verdadeiro self, um eu-corpo seriamente mutilado. O conto termina com uma demanda:

Por favor, empreste-me sua mão.

Por favor, cave este buraco sem fim.

Annie e eu descobrimos na transferência, como Fritz Zorn em sua terapia, a figura assustadora de seus pais interiorizados, dos quais ela livrou-se pagando o preço de uma mutilação interna que causava um buraco, e que ela pedia-me para "cavar" com ela, ou seja, para lhe encontrar um sentido. Este buraco vazio de sentido era, de fato, um excesso, um excesso de excitações vazio de sentido (os fueros ${ }^{11}$ para Freud (1986, p.155-156) diretamente em seu corpo e sua pessoa, que provocava um turbilhão e que alimentava um sentimento-sensação de descontinuidade, de contra-senso que parecia aspirála, "grudá-la”. Délia falava, a este respeito, em "colocar uma camada de branco (de typex) ou de vazio sobre algo excessivo".

A presença do outro não preenche jamais uma solidão fundamental. Pelo contrário, “que ele seja presente ou ausente, é doloroso”, dizia Délia, a propó-

\footnotetext{
${ }^{11}$ Freud utiliza o termo espanhol fueros para designar "traços do passado (que) sobreviveram". Segundo a carta a Fliess de 6 de dezembro de 1896, estes traços constituiriam, aquém do inconsciente e do consciente, "o primeiro registro das percepções, totalmente incapaz(es) de tornar(em)-se consciente(s) e organizadas segundo as associações simultâneas [...]. A lembrança age, então, como um acontecimento atual" (p.155-156).
} 
sito de seu namorado. Contudo, a perda do outro, no presente, pode reabrir uma falha essencial, melhor ou pior colmatada: para Annie, sua mãe a havia deixado em sua irmã (a tia materna), enquanto tinha dois meses e meio, para reencontrar, com seus filhos mais velhos, seu marido, enviado por nove meses com sua guarnição no Marrocos. Além disso, Annie acreditava profundamente que sua mãe jamais a amara. Ela queria um menino em seu lugar. Assim como Zorn, a terapia proporcionou-lhe algumas alegrias não negligenciáveis e a esperança de poder viver sentindo-se aceita, mas ela não foi suficiente para distanciá-la suficientemente de sua história catastrófica, que não desenvolverei aqui.

\section{CONCLUSÃO}

O autista consegue, de maneira radical, rejeitar qualquer interiorização de seus pais; o adicto e o somatizante não exercem uma rejeição tão clara. Eles interiorizam o outro, mas enquanto não-pessoa, como uma coisa em si insatisfatória, como um excesso excitante que perverteu seu contato com o mundo em suas próprias origens. Nas três síndromes, é a constituição total ou parcial do eucorpo que é atingida como conseqüência da ausência de apoio das pulsões no outro e, pelo retorno sobre si, no próprio corpo. Para estes sujeitos, o fracasso resulta da privação, total ou parcial, da primeira camada do aparelho psíquico, o pára-excitações, em princípio continente e fonte de segurança. Neles, é furado e cria procedimentos de autoconservação paradoxais, que imitam uma espécie de inversão ou de avesso do processo auto-erótico sob fundo de desfusão de Eros e de Tanatos, em proveito deste último.

Esta desfusão deixa Tanatos soberano. Sozinho, Tanatos dá sobretudo ao outro uma valência mortífera. O primeiro suporte de apoio das pulsões, o corpo, ao invés de ser investido pela libido, é então atacado em suas próprias funções, seja ao nível de suas experiências sensuais de base, rir, chorar, tocar, como no autista Birger Zellin, seja pela absorção de substâncias que "quebram” o poder de agir e de pensar, seja por um distúrbio somático que, à revelia do sujeito, coloca sua vida biológica em perigo. Neste sentido, a anorexia não se encontraria mais no cruzamento da adicção e da somatização do que na simples adicção? De qualquer maneira, estes três modos de autoconservação paradoxais, que tendem a proteger alguns nacos da identidade subjetiva ou da continuidade do ser, geram, devido ao ataque à primeira tentativa de apoio, a impossibilidade para o eu, particularmente o eu-corpo, de constituir-se sem clivagem, ou seja, sem estes buracos/excessos que constituem pontos de apelo de desamparo e que reaparecem desde que situações afetivas os reativem (o abandono de Annie por seu amante, por exemplo). Um câncer não se desenvolve a qualquer momento, mas com freqüência quando o outro amado é fonte de mal-estar. Do mesmo modo, a adicção se declara quando se torna claro que o sujeito só 
precisa verdadeiramente do outro como substância. Tal clivagem se produz quase sempre na adolescência, no momento do trabalho de separação dos objetos primários, objetos que são mais nutridores do que portadores de sentido.

Assim, o objeto autístico, adictivo e o objeto somático não representam o objeto primário, eles o substituem e criam condições paradoxais de uma repetição autística da destruição do outro.

Engendrar um lugar psíquico para que este outro, que até então era apenas coisa excitante ou supereu cruel, torne-se ausência metabolizada, dali em diante plena, matriz do ser interno, é a obra transferencial de uma análise ou de uma psicoterapia. Mas, escreve McDougall, “se o analista mantém sua função clássica de espelho refletor face às dimensões faltantes do vivido psíquico e face ao vivido somático destes analisandos — ou seja, se ele se obstina em manter seu espelho sempre no mesmo lugar e no mesmo ângulo — - ele só pode refletir este nada (este excesso de excitações) que são a representação destruída e o afeto estrangulado. Convém distinguir entre a falta, significância que induz o desejo e a criatividade, e este nada irrepresentável, indizível, metáfora da morte. Terreno limite do analisável”, acrescenta McDougall (1978, p.172).

Como sustentar este lugar de suporte do outro que favoreça a passagem das formas mudas, inertes, que alimentam um masoquismo mortífero terrível para o eu-corpo autístico, adictivo ou somatizante, a formas fantasmáticas vivas, capazes de se autogerar? “A topologia da observação, propõe Fédida em seu artigo intitulado "Autismo e auto-erotismo. Condições de eficácia de um paradigma em psicopatologia”, exige palavras que sejam elas próprias atos sensoriais de significação" (1990, p.402-403). Esta proposta de uma escuta poética é essencial, mas não exclui outras modalidades.

Segundo o grau de destruição ou de não-constituição do pára-excitações e do eu-corpo, o recurso ao uso de suportes plásticos e figurativos poderá ser pertinente para relançar o destino auto-erótico da pulsão e da atividade de representação fantasmática proveniente dela.

Além disso, o terror, o ódio ou a inextricável ambivalência reativadas pelo outro (o “nó de ilusão negativa paranóica” (ROUSSILLON, 1999, p.204), particularmente na relação dual e que introduz, não em uma problemática do conflito, mas em uma problemática do laço, assim como indica Ph. Jeammet, necessitam do recurso a "terapias bi- ou multifocais, com referentes que se situem no nível da realidade externa e de uma arrumação desta realidade, com, eventualmente, intervenientes no nível familiar” (JEAMMET, 1995, p.172-173).

Enfim, em referência ao artigo de Freud de 1938, "Construções em análise”, no que concerne ao tratamento destes traumatismos primitivos que se fundamentam em uma carência na organização dos auto-erotismos e em uma forte tendência ao ato, R. Roussillon propõe "um trabalho de historização do sinto- 
ma somático (entre outros) a partir de um trabalho de recontextualização da "sensação perceptiva" (os fueros) (ROUSSILLON, 1999, p.136), a fim de que ela ascenda à ordem da simbolização primária. A terapia dos estados de autismo e de psicose infantil conduziram-me a uma proposição análoga (ALLOUCH, 1999, p.216-225).

Abstrair-se autisticamente, adictar-se, somatizar são, profundamente, a mesma coisa. Todos os três denotam graus de fracasso no apoio. Se bem sucedido, o apoio preserva o sujeito das reações paradoxais de autoconservação, dominadas pela busca exacerbada de sensações, que preenchem a falta do laço corpo/ psyché, tributário da qualidade do primeiro laço afetivo. Orquestradas pela presença de um outro, estimulante e assegurador, as "experiências sensoriais de base” (expressão de Tustin) forjam o fundo vital que permite viver criativamente em um corpo e além, com os outros e os objetos do mundo através da linguagem, ao invés de sobreviver autodestruindo-se. Às bordas de uma fascinação pela e para a morte (sob o impacto de um narcisismo de morte), somatizar, adictar-se, abstrair-se autisticamente são tentativas de abandonar um estado de solidão fundamental, definição possível do autismo em seus círculos infernais, que incluem as adicções e as somatizações, aproximando demais a morte.

\section{REFERÊNCIAS}

ALLOUCH, E. (1999) Au seuil du figurable / Autisme, psychose infantile et téchniques du corps, col. Voix nouvelles en psychanalyse. Paris: PUF.

. (2000) Les conditions narcissiques de la parole, in Revue Psychologie Clinique et Projective (organisation et désorganisation psychiques chez l'enfant), dez., v.6, p. $175-186$.

. (2002) "Un géométral hallucinatoire: autisme et hallucination négative”, in Psychologie clinique (Corps, affect, émotion), Paris: L’Harmattan, n. 10, inverno, p.115-127.

DERRIDA, J. (1968) La pharmacie de Platon, Tel quel n. 32.

FÉDIDA, P. (1990) Auto-érotisme. Conditions d'efficacité d'un paradigme en psychopathologie, in Revue Internationale de Psychopathologie, Paris: PUF, n. 2, p.395-413.

. (1995) L'addiction d'absence, l'attente de personne, in Cliniques Méditerranéennes n.47/48, p.9-21.

FERENCZI, S. (1929/1982) “L’enfant mal accueilli et sa pulsion de mort”, in Oeuvres complètes, t. 4, Paris: Payot. 
FREUD, S. (1986) “Lettre (à W. Fliess) n.52 de 6/12”, in Naissance de la psychanalyse. Paris PUF.

. (1913/1993) “Animisme, magie et toute-puissance des pensées”, in Totem et tabou. Paris: Gallimard.

. (1915) "Pulsions et destins des pulsions", in Oeuvres complètes,

t. XIII. Paris: PUF.

(1920) “Au-delà du principe du plaisir”, in Essais de Psychanalyse. Paris: Payot.

(1923) "Les relations de dépendance du moi", in Essais de psychanalyse. Paris: Payot.

. (1923) "Le moi et le ça”, in Essais de Psychanalyse. Paris: Payot.

HAAG, G. (1985) De l'autisme à la schizophrénie chez l'enfant, in Topique n.35-36. Paris.

GRANDIN, T. (1986/2001) Ma vie d'autiste (Emergence: Labeled Autistic). Paris: Odile Jacob

JEAMMET, Ph. (1995) Psychopathologie des conduites de dépendance et d'addiction à l'adolescence, in Cliniques méditerranéennes, n.47 / 48.

KANNER, L. (1942-43/1983) “Autistic disturbances of affectif contact”, in Nervous Child, 3, 2, p. 217-230; Tradução para o francês de Berquez G., in L'autisme infantil. Paris: PUF.

KREISLER, L., FAIN, M., SOULÉ M. (1974) L’enfant et son corps. Paris: PUF. Le fil rouge.

LE POULICHET, S. (1987) Toxicomanie et Psychanalyse, Les narcoses du désir. Paris: PUF.

MCDOUGALL, J. (1978) Pladoyer pour une certaine normalité. Paris: Gallimard. (1989) Théatre du corps. Paris: Gallimard.

(1996) “Néo-besoins et solutions addictives", in Eros aux mille et un visages. Paris: Gallimard.

MELTZER, D., BRENNER, J., HOXTER, S., WEDDEL, D., WITTENBERG, I. (1975) Exploration dans le monde de l'autisme. Paris: Payot.

MICHAUX, H. (1967/1984) Connaissance par les gouffres. Paris: Gallimard (NRF).

(1994) “Trahison du corps", in Oeuvres complètes I. Paris: Bibliotèque de la Pléiade. Pléiade.

ROSEMBERG, B. (1991/1995) "Masochisme mortifère et masochisme gardien de vie" in Monographies de la Revue Française de Psychanalyse. Paris PUF.

ROSENFELD, D. (1997) Autisme: des aspects autistiques de la pharmacodépendance et dans les maladie somatiques, in Journal de Psychanalyse de L'enfant (Le Corps) n.20. Paris: Bayard-éditions.

ROUSSILLON, R. (1991) Paradoxes et situations limites de la psychanalyse. Paris: PUF.

(1999) Agonie, clivage et symbolisation. Paris: PUF. Le fait psychanalytique.

SELLIN, B. (1993/1994) Une âme prisonnière. Paris: Réponses/Robert Laffont. TUSTIN, F. (1972/1977) Autisme et psychose de l'enfant. Paris: Points/Seuil. 
(1985) “Améliorer les états autistiques”, in Lieux d'enfance.

Privat, 3, p.221-246.

(1989) Le trou noir de la psyché. Paris: Seuil.

(1990/1992) Autisme et protection (The protective shell in children and adults). Paris: Seuil.

WINNICOTT, D. W. (1949) “L’esprit et ses rapports avec le psyché soma”, in De la pédiatrie à la psychanalyse. Paris: Payot

ZORN, F. (1977/1979) Mars, Paris: Gallimard, Folio.

\author{
Eliane Allouch \\ 10, rue Erard \\ C 37175012 Paris France \\ elianeallouch@hotmail.com
}

